This item was submitted to Loughborough's Research Repository by the author.

Items in Figshare are protected by copyright, with all rights reserved, unless otherwise indicated.

\title{
Fractional integration and the volatility of UK interest rates
}

PLEASE CITE THE PUBLISHED VERSION

http://dx.doi.org/10.1016/j.econlet.2012.04.015

PUBLISHER

(c) Elsevier

VERSION

AM (Accepted Manuscript)

LICENCE

CC BY-NC-ND 4.0

REPOSITORY RECORD

Coleman, Simeon, and Kavita Sirichand. 2019. "Fractional Integration and the Volatility of UK Interest Rates". figshare. https://hdl.handle.net/2134/14770. 
This item was submitted to Loughborough's Institutional Repository (https://dspace.lboro.ac.uk/) by the author and is made available under the following Creative Commons Licence conditions.

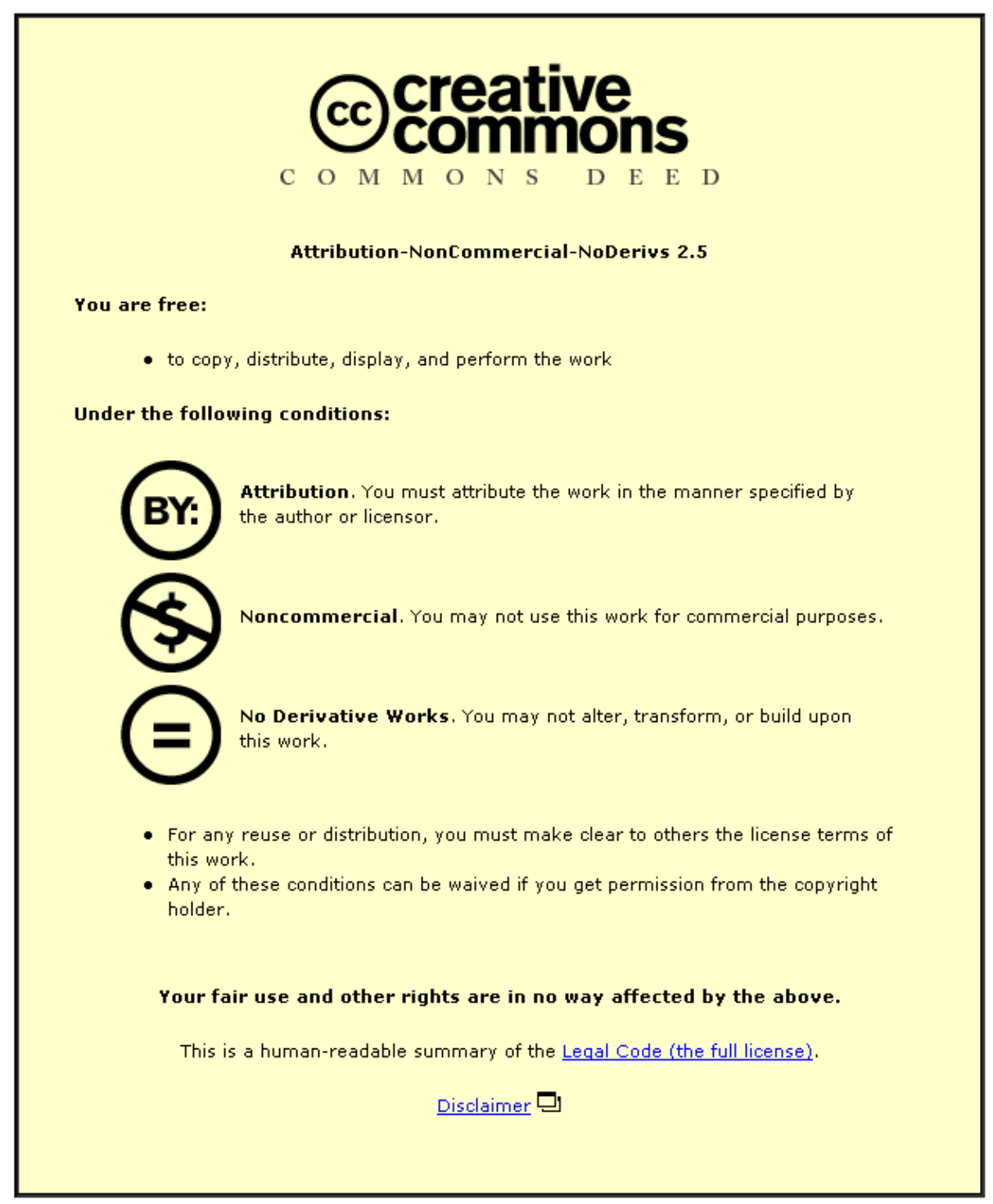

For the full text of this licence, please go to: http://creativecommons.org/licenses/by-nc-nd/2.5/ 


\title{
Fractional integration and the volatility of UK interest rates
}

\author{
Simeon Coleman ${ }^{a, *}$ and Kavita Sirichand ${ }^{b}$ \\ ${ }^{a}$ Economics Division, Nottingham Business School, Nottingham Trent University, Burton Street, Nottingham, NG1 4BU, UK. \\ Email: simeon.coleman@ntu.ac.uk \\ ${ }^{b}$ School of Business and Economics, Loughborough University, Loughborough, LE11 3TU, UK. \\ Email: k.sirichand@lboro.ac.uk
}

\begin{abstract}
We find that short rates are more nonstationary than longer rates and differences in conditional volatility exist between different maturities. Therefore, their dynamics may be both maturity-specific and country-specific and any a priori generalizing assumptions may be misleading.
\end{abstract}

Keywords: fractional integration, interest rates, conditional volatility

JEL Codes: C22, E43

\section{Introduction}

The importance of interest rates in finance and economics is well established, they are fundamental in monetary policy formulation and to investment decision making. As such, it is essential to have a thorough understanding of the dynamic behavior of interest rates.

Empirically, interest rates are found to exhibit I(1) behavior, see Campbell and Shiller (1991), Cuthbertson et al. (2000) and Mishkin (1992). However, Tkacz (2001) and Lopes and Monteiro (2007) highlight that the theoretical implication of interest rates following a unit-root process without drift is that there are no bounds on its movements, suggesting the possibility of negative nominal rates. A further implication is that shocks have a permanent effect. In more recent examinations of real rates, Tsay (2000), Tsakz (2001), Candelon and Gil-Alana (2006), and Karanasos et al. (2006) conclude in favor of fractional integration methods as opposed to the knife-edge $\mathrm{I}(0) / \mathrm{I}(1)$ approach.

Improved knowledge of interest rate dynamics is crucial for modeling and forecasting. First, their dynamics are central to the valuation of financial assets and the study of well-known macroeconomic models. ${ }^{1}$ Second, the flexibility and recent developments in the use of long memory tests with good size and power can provide better insights. Third, much of the existing empirical evidence, concerning

\footnotetext{
* Corresponding author Tel.: +44 1158486007; fax: +44 1158488010. E-mail address: simeon.coleman@ntu.ac.uk (S. Coleman)

${ }^{1}$ For example the Fisher hypothesis and the uncovered interest rate parity hypothesis.
} 
the order of integration, focuses on US ex-ante and ex-post rates. Despite its importance, and the substantial literature devoted to the topic, the jury is still out on the order of integration of interest rates.

In this paper, our empirical analysis has two aims: First, to examine the order of integration of the short and long rates over two periods, defined as Pre (5/03/1997-28/03/2007) taken as the pre-crisis period and Post (4/04/2007-28/07/2010) which includes the crisis period, to determine if idiosyncratic differences exist between the maturities and across periods. We address this aim by employing fractional integration (FI) tests, which are more flexible compared to standard unit-root tests, testing the validity of the common practice of imposing $\mathrm{I}(0) / \mathrm{I}(1)$ conditions. $^{2}$ Second, to investigate volatility in these rates over the stated periods, to see which, if any, rate exhibits higher volatility and if this volatility changed over the periods. This aim is addressed by employing GARCH modeling techniques, allowing us to comment on asymmetries in conditional volatility around their means.

The remainder of the paper is organized as follows. Section 2 summarizes the econometric techniques and the main results, and Section 3 concludes.

\section{Econometric methodology and results}

\subsection{Data}

We use weekly observations of UK risk-free discount bonds for maturities of 6, 12 and 120 months (hereafter $r 6, r 12$ and $r 120$ ) between 5/03/1997-28/07/2010. ${ }^{3}$ Visual inspection of r6, $r 12$ and r120, (Figure 1) suggests significant co-movement in the rates until mid-2008, after which $r 6$ and $r 12$ dipped significantly. See Table 1 for summary statistics.

\footnotetext{
${ }^{2}$ For an $\mathrm{I}(0)$ process shocks decay at an exponential rate; for an $\mathrm{I}(1)$ process shocks have permanent effect and for an $\mathrm{I}(d)$ process shocks dissipate at a slow hyperbolic rate.

${ }^{3}$ We use official Bank of England (BoE) data on the Government liability curve. Specifically, Wednesday observations of nominal government spot rates are employed, where the yields are continuously compounded.
} 
Figure 1: Time-series plots of interest rate series March'97-July'10



Table 1: Summary Statistics

\begin{tabular}{lcccccc}
\hline & \multicolumn{2}{c}{$r 6$} & \multicolumn{2}{c}{$r 12$} & \multicolumn{2}{c}{$r 120$} \\
\hline & Pre & Post & Pre & Post & Pre & Post \\
Mean & 5.023 & 2.796 & 5.042 & 2.779 & 4.988 & 4.313 \\
Maximum & 7.410 & 5.890 & 7.27 & 5.880 & 7.65 & 5.390 \\
Minimum & 3.180 & 0.340 & 3.160 & 0.560 & 3.900 & 3.190 \\
Std. Dev. & 1.073 & 2.319 & 1.035 & 2.159 & 0.704 & 0.565 \\
Observations & 520 & 173 & 520 & 173 & 520 & 173 \\
\hline
\end{tabular}

\subsection{Unit root tests}

To ascertain which rates can be better explained by stochastic processes or deterministic factors, we conduct Augmented Dickey-Fuller (1979) [ADF], Kwiatkowski et al. (1992) [KPSS], and Ng and Perron (2001) [NP] unit root tests. ${ }^{4}$

Under the ADF test the null of a unit root for $r 6$ and $r 12$ cannot be rejected for both Pre and Post periods; however, it is rejected for r120 in the Pre but not the Post period. Under the KPSS test the null of stationarity is unambiguously rejected and under the NP test the null of a unit root cannot be rejected, in each series over both periods. The inconclusive results (see Table 2), particularly for $r 120$, underscore the need to go beyond the $\mathrm{I}(1) / \mathrm{I}(0)$ framework, making FI tests instructive.

\footnotetext{
${ }^{4}$ The NP test combines a Modified Information Criterion for the lag length and a Generalized Least Squares method for detrending the data, it proposes four test statistics: $M Z_{a}, M Z_{t}, M S B$ and the MPT. In addition to the conventional ADF, KPSS and NP individual unit root tests, we also conduct three panel unit root tests, namely the Levin et al. (2002), Im et al. (2003) and ADF-Fisher Chi Square tests. Similarly, these results of these tests are inconclusive and are not reported here, but are available upon request.
} 
Table 2: Unit root tests

\begin{tabular}{|c|c|c|c|c|c|c|c|}
\hline & \multicolumn{3}{|c|}{ r6 } & \multicolumn{2}{|c|}{$r 12$} & \multicolumn{2}{|c|}{ r120 } \\
\hline & \multicolumn{2}{|c|}{ Pre } & Post & Pre & Post & Pre & Post \\
\hline $\mathrm{ADF}$ & \multicolumn{2}{|c|}{-0.146} & -1.196 & -1.260 & -1.227 & $-3.304^{* *}$ & -1.577 \\
\hline KPSS & \multicolumn{2}{|c|}{$1.638^{*}$} & $1.491^{*}$ & $1.706^{*}$ & $1.486^{*}$ & $1.659 *$ & $1.161 *$ \\
\hline \multicolumn{8}{|l|}{ NP } \\
\hline$M Z_{\alpha}^{G L S}$ & \multicolumn{2}{|c|}{-1.769} & -0.240 & -0.888 & -0.483 & -0.016 & -2.305 \\
\hline$M Z_{t}^{G L S}$ & \multicolumn{2}{|c|}{-0.925} & -0.154 & -0.633 & -0.283 & -0.016 & -0.891 \\
\hline$M S B^{G L S}$ & \multicolumn{2}{|c|}{0.523} & 0.642 & 0.712 & 0.587 & 0.961 & 0.386 \\
\hline$M P_{T}^{G L S}$ & \multicolumn{2}{|c|}{13.636} & 25.783 & 25.566 & 21.530 & 52.077 & 9.486 \\
\hline \multicolumn{8}{|c|}{$\begin{array}{l}\text { Notes: } * * * * * \text { and } * \text { indicates null rejected at } 10 \%, 5 \% \text { and } 1 \% \text { respectively. The critica } \\
3.127,-3.411 \text { and }-3.961 \text {, and for the KPSS test are } 0.216,0.146 \text { and } 0.119 \text { at the } 10 \%, 5 \\
\text { and Perron tests include an intercept and the lag order was chosen using the modified AIC }\end{array}$} \\
\hline & Fractile & $\mathrm{MZ}_{\alpha}^{\mathrm{GLS}}$ & $\mathrm{MZ}_{\mathrm{t}}^{\mathrm{GLS}}$ & $\mathrm{MSB}^{\mathrm{GLS}}$ & $\mathrm{MP}_{\mathrm{T}}^{\mathrm{GLS}}$ & & \\
\hline & $1 \%$ & -13.80 & -2.58 & 0.17 & 1.78 & & \\
\hline & $5 \%$ & -8.10 & -1.98 & 0.23 & 3.17 & & \\
\hline & $10 \%$ & -5.70 & -1.62 & 0.27 & 4.45 & & \\
\hline
\end{tabular}

\subsection{Fractional integration tests}

Long memory in macroeconomic variables is well established. ${ }^{5} \quad$ Granger and Joyeux (1980) and Hosking (1981) showed that a long memory process for $y_{t}$ can be modeled as a fractionally integrated, $\mathrm{I}(d)$, process

$$
(1-L)^{d}\left(y_{t}-\mu\right)=\varepsilon_{t}
$$

where $L$ denotes the lag operator, $d$ is fractional difference parameter, $\mu$ is the unconditional mean of $y_{t}$, and $\varepsilon_{t}$ is stationary with zero mean and finite variance. A flexible parametric process of order $(p, d, q)$ called the ARFIMA $(p, d, q)$ model incorporates both long-term and short-term memory.

$$
\Phi(L)(1-L)^{d}\left(y_{t}-\mu\right)=\varphi(L) \varepsilon_{t}
$$

where $\Phi(L)$ and $\varphi(L)$ are autoregressive and moving average polynomials, respectively, with roots that lie outside the unit circle and $\varepsilon_{t}$ is Gaussian white noise. $y_{t}$ is stationary provided $d €(-0.5,0.5)$; however, its lagged autocovariance decreases very slowly exhibiting long memory, see Table $3 .{ }^{6}$

\footnotetext{
5 See examples Baum et al. (1999a, 1999b) and references cited therein.

$6 y_{t}$ is invertible when $d>-0.5$. For detailed discussions of long memory testing and estimation methods, we refer the interested reader to Baillie (1996) and Baum et al. (1999a, 1999b).
} 
Table 3: Summary of fractional integration parameter values

\begin{tabular}{clll}
\hline$d$ & Variance & Shock duration & Stationarity \\
\hline$d=0$ & Finite & Short-lived & Stationary \\
$0<d<0.5$ & Finite & Long-lived & Stationary \\
$0.5 \leq d<1$ & Infinite & Long-lived & Nonstationary \\
$d=1$ & Infinite & Infinite & Nonstationary \\
$d>1$ & Infinite & Infinite & Nonstationary \\
\hline Source: Tkacz (2001) & &
\end{tabular}

We report in Table 4, the Modified Log-Periodogram Regression estimator proposed by Phillips (1999a, 1999b), which requires a choice of the number of harmonic ordinates to include in the spectral regression. For robustness, we use a range of powers $(0.50-0.65){ }^{7}$

Table 4: Modified Log-Periodogram Regression estimator [Phillips (1999a, 1999b) procedure]

\begin{tabular}{|c|c|c|c|c|c|c|c|c|}
\hline \multicolumn{9}{|c|}{ Fractional Integration test statistic (Modlpr) } \\
\hline power & \multicolumn{2}{|c|}{0.50} & \multicolumn{2}{|c|}{0.55} & \multicolumn{2}{|c|}{0.60} & \multicolumn{2}{|c|}{0.65} \\
\hline & Pre & Post & Pre & Post & Pre & Post & Pre & Post \\
\hline r6 & $1.2^{*, \wedge \wedge \wedge}$ & $1.4^{*, \wedge \wedge}$ & $1.4^{*, \wedge}$ & $1.5^{*, \wedge}$ & $1.3^{*, \wedge}$ & $1.3^{*, \wedge \wedge}$ & $1.2 *, \wedge \wedge \wedge$ & $1.3^{*, \wedge \wedge}$ \\
\hline$r 12$ & $1.2^{*}$ & $1.6^{*, \wedge}$ & $1.3^{* \wedge \wedge}$ & $1.5^{*, \wedge}$ & $1.2^{*, \wedge}$ & $1.4^{*, \wedge}$ & $1.1^{*}$ & $1.3^{*, \wedge \wedge}$ \\
\hline r120 & $1.0^{*}$ & $0.8^{*}$ & $0.9 *$ & $1.0 *$ & $0.8^{*}$ & $1.1^{*}$ & $0.9^{*}$ & $1.1 *$ \\
\hline
\end{tabular}

Here, the null of $d=0$ is consistently rejected at all power levels in both periods. Some further observations are noteworthy. First, under the Phillips test, which also provides a $z$-statistic to determine whether $d$ is significantly different from 1, for both $r 6$ and $r 12$ (unlike $r 120$ ), there is a high tendency to reject the null of $d=1$ across powers, suggesting that $d>1$ i.e. explosive behavior. ${ }^{8}$ This contrasts sharply to the findings of Tkacz (2001) for the USA and Canada, who finds shorter rates to be less nonstationary than longer rates. We posit that since UK short rates tend to remain at the same level for prolonged periods before changing, it is likely that these 'stepwise' movements may be misinterpreted as structural breaks by the FI tests. Second, the $d$ estimates for the Post period appear to be larger than that for the Pre period, suggesting higher tendency of non mean-reversion. This result can be explained by the fact that the Post period includes the current financial crisis, and this

\footnotetext{
7 A desirable property of this procedure is that the dependent variable is modified to reflect the distribution of $d$ under the null hypothesis that $d=1$. The estimator gives rise to a test statistic for $d=1$ which is a standard normal variate under the null. The regression slope estimate is an estimate of the slope of the series' power spectrum in the vicinity of the zero frequency; if too few ordinates are included, the slope is calculated from a small sample. If too many are included, medium and high-frequency components of the spectrum will contaminate the estimate.

${ }^{8}$ As a robustness check, FI was also tested using two other widely used procedures suggested by Geweke and Porter-Hudak (1983) and Robinson (1995) in STATA11. The results unequivocally confirm the rejection of the null of $d=0$ for each series. In addition, autocorrelation functions for each series (not shown here) confirm that the decay in r120 (approximately 60weeks) is faster than in $r 6$ and $r 12$ (approximately 160 weeks).
} 
sample period is not long enough for mean reversion to be observed i.e. interest rates have not started adjusting yet and have not begun reverting to their respective means.

\subsection{Volatility testing}

We first experimented with different combinations of model orders and found that a GARCH $(1,1)$ model provided the best fit for our series. ${ }^{9}$ In the context of interest rates, our aim is to capture the series' variance dependence (if any) on a weighted average of the long term average of the series, news about volatility from the previous period $(\alpha)$ and last period's forecast variance $(\beta)$ respectively. Table 5 summarizes our results. ${ }^{10}$

Table 5: Tests for Volatility

\begin{tabular}{|c|c|c|c|c|}
\hline & \multicolumn{2}{|c|}{ Pre } & \multicolumn{2}{|c|}{ Post } \\
\hline & $\underline{\operatorname{GARCH}(1,1)}$ & IGARCH & $\underline{\operatorname{GARCH}}(1,1)$ & IGARCH \\
\hline r6 & & & & \\
\hline $\mathrm{c}$ & $0.004 *$ & & $0.040 \%$ & \\
\hline GARCH(-1) & -0.085 & $0.309^{*}$ & $-0.503 * *$ & $-2.743^{*}$ \\
\hline $\operatorname{Resid}(-1)^{2}$ & $1.111 \%$ & $0.691^{*}$ & $1.326^{*}$ & $3.743^{*}$ \\
\hline 112 & & & & \\
\hline $\mathrm{c}$ & 0.012 & & 0.000 & \\
\hline GARCH(-1) & بّ بّ & $0.395^{*}$ & $0.574 \%$ & $-2.244^{*}$ \\
\hline $\operatorname{Resid}(-1)^{2}$ & $1.133^{*}$ & $0.605^{*}$ & $0.386^{*}$ & $3.244^{*}$ \\
\hline$r 120$ & & & & \\
\hline $\mathrm{c}$ & $0.008^{*}$ & & $0.003 * * *$ & \\
\hline GARCH(-1) & $-0.040 * * *$ & $0.545 *$ & $0.345^{*}$ & $0.523^{*}$ \\
\hline $\operatorname{Resid}(-1)^{2}$ & $0.995^{*}$ & $0.455 \%$ & $0.709 *$ & $0.477 *$ \\
\hline
\end{tabular}

Notes: $*, * *, * * *$ implies null of no significance rejected at $1 \%, 5 \%$ and $10 \%$ respectively. Based on the FI tests, the preferred model's result is in bold font.

Following the FI estimates (Table 4), where the null of $d=1$ is rejected, the GARCH(1,1) model is applied. In which case, $\alpha+\beta<1$ infers mean-reversion, and $\alpha+\beta>1$, explosive behavior. Where the null cannot be rejected for a given series, an IGARCH model, which restricts $\alpha+\beta=1$ is employed. Therefore, we model $r 6$ and $r 12$ using GARCH(1,1) and r120 using an IGARCH model.

For the short rates, there is higher dependence of current volatility on the previous period's volatility and unsurprisingly it is higher in the Post period, this suggests a higher tendency for

\footnotetext{
${ }^{9}$ Notably, the conditional variance $\left(\sigma_{t}^{2}\right)$ is the one-period ahead forecast variance based on past information - a constant term (ø) and the ARCH term $\left(\varepsilon_{t-1}\right)$ and GARCH term $\left(\sigma_{t-1}^{2}\right)$.

${ }^{10}$ We allow for the possibility that residuals are not conditionally normally distributed, by computing the Heteroskedasticity Consistent Covariance.
} 
explosive behavior in short rates. However, for the long rate there appears to be consistency in volatility over both periods.

\section{Concluding remarks}

This paper contributes to the debate on the order of integration of nominal interest rates by analyzing rates with differing terms to maturity. We show that the dynamic properties of short and long rates are inherently different. First, contrary to previous studies for the US and Canada, our results suggest that, in the UK, shorter rates are more nonstationary than long rates. Second, using GARCH techniques to measure uncertainty, we find that volatility in the short rates tend to be more dependent on news about volatility from the previous period; whereas the long rate tends to be fairly equally dependent on the level of, and news about volatility of the previous period. The level of volatility in the Post period appears to be more relevant than in the Pre period. In conclusion, term to maturity and origin country appear to be important factors for the order of integration of interest rates, so a priori generalizing assumptions about the order of integration of interest rates may be misleading.

\section{Acknowledgements}

The authors would like to thank Stephen Hall, Barry Harrison, and Vitor Leone for their instructive comments they provided on an earlier version of the paper. All remaining errors are ours.

\section{References}

Baillie, R.T., 1996. Long memory processes and fractional integration in econometrics. Journal of Econometrics. 73, 5-59.

Baum, C.F., Barkoulas, J.T., Caglayan, M., 1999a. Persistence in international inflation rates. Southern Economic Journal. 65, 900-913.

Baum C.F., Barkoulas, J.T., Caglayan, M., 1999b. Fractional monetary dynamics. Applied Economics. 31,1393-1400.

Campbell, J., Shiller, R. J., 1991. Yield spreads and interest rate movements: a bird's eye view. Review of Economic Studies. 58, 495-514. 
Candelon, B., Gil-Alana, L. A., 2006. Mean reversion of short run interest rates in emerging countries. Review of International Economics. 14, 119-135.

Cuthbertson, K., Hayes, S., Nitzsche, D., 2000. Are German money market rates well behaved? Journal of Economic Dynamics and Control. 24, 347-360.

Dickey, D.A., Fuller W.A., 1979. Distribution of the estimators for autoregressive time series with a unit root. Journal of the American Statistical Association. 74, 427-431.

Geweke, J., Porter-Hudak, S., 1983. The estimation and application of long memory models. Journal of Time Series Analysis. 4, 221-238.

Granger, C.W.J., Joyeux, R., 1980. An introduction to long memory time series models and fractional differencing. Journal of Time Series Analysis. 1, 15-39.

Hosking, J.R.M., 1981. Fractional differencing. Biometrika. 68, 165-176.

Im, K.S., Pesaran, M.H., Shin, Y., 2003. Testing for unit roots in heterogeneous panels. Journal of Econometrics. 115, 53-74.

Karanasos, M., Sekioua, S. H. and Zeng, N., 2006. On the order of Integration of monthly US ex-ante and ex-post real interest rates: New evidence from over a century of data. Economics Letters. 90, 163169.

Levin, A., Lin, C.F., Chu, C., 2002. Unit root tests in panel data: asymptotic and finite sample properties. Journal of Econometrics. 108, 1-24.

Lopes, A. C., Monteiro, O. S., 2007. The expectations hypothesis of the term structure: some empirical evidence for Portugal. MPRA Paper No. 3437.

Mishkin, F. S., 1992. Is the Fisher effect for real? a reexamination of the relationship between inflation and interest rates. Journal of Monetary Economics. 30, 195-215.

Ng, S., Perron, P., 2001. Lag length selection and the construction of unit root tests with good size and power. Econometrica. 69, 1519-1554.

Phillips, P. C. B., 1999a. Discrete fourier transforms of fractional processes. Unpublished working paper No. 1243, Cowles Foundation for Research in Economics, Yale University.

Phillips, P. C. B., 1999b. Unit root log periodogram regression. Unpublished working paper No. 1244, Cowles Foundation for Research in Economics, Yale University.

Robinson, P.M., 1995. Log-periodogram regression of time series with long range dependence. Annals of Statistics. 23, 1048-1072.

Tkacz, G., 2001. Estimating the fractional order of integration of interest rates using wavelet OLS estimator. Studies in Nonlinear Dynamics and Econometrics. 5, 1-21.

Tsay, W. J. (2000). The long memory story of the real interest rate. Economics Letters. 67, 325-330. 